\title{
Exploring the Impact of Augmented Reality and Virtual Reality Technologies on Business Model Innovation in Technology Companies in Germany
}

\author{
Richard Hagl \\ The School of Business \\ The Department of Graduate Business \\ Waterford Institute of Technology (WIT) \\ Cork Road, Waterford City, Ireland \\ Email: hagl@phaenom.eu
}

\author{
Aidan Duane \\ The School of Business \\ The Department of Graduate Business \\ Waterford Institute of Technology (WIT) \\ Cork Road, Waterford City, Ireland \\ Email: aduane@wit.ie
}

\begin{abstract}
Newly-emerging, digitally-based technological innovations, such as augmented reality (AR) and virtual reality (VR), are new drivers for business model innovation. This study aims to develop a better understanding of the impact of AR/VR technologies on business model innovation in technology companies. The objective of the study is "to explore the impact of augmented reality and virtual reality technologies on business model innovation in technology companies in Germany". This paper investigates the body of knowledge regarding contemporary business model innovation and presents a conceptual framework to guide the research. The philosophical underpinnings of the study are discussed, and the chosen research methodology is justified. A holistic multiple-case study design targets German business-to-business technology companies employing AR/VR technologies to innovate their business models. The paper concludes with a discussion of initial learnings garnered from the implementation of a pre-pilot case study test run, and a full pilot case study.
\end{abstract}

Keywords Augmented Reality, Virtual Reality, Business Models, Business Model Innovation, Case Studies.

Copyright: (C) 2018 authors. This is an open-access article distributed under the terms of the Creative Commons Attribution-NonCommercial 3.0 Australia License, which permits non-commercial use, distribution, and reproduction in any medium, provided the original author and ACIS are credited. 


\section{INTRODUCTION}

Digital technologies such as augmented reality (AR) and virtual reality (VR) are drivers for business model innovation (BMI) (Casadesus-Masanell and Ricart 2011), and business models themselves may be shaped by technological innovations (Teece 2006). This is especially true in the high velocity environment of the internet, where business models must be frequently altered to meet new challenges. These technologies are expected to offer significant revenue opportunities in numerous industries in the next few years (Ebert et al. 2017). However, new technologies - such as AR/VR - oftentimes have no obvious business case (Chesbrough 2010), and little is known about their impact on BMI. Zott et al. (2011) note that "academic research on business models seems to lag behind practice" (p.1022) and that "prior frameworks used in isolation cannot sufficiently address questions about total value creation" (p.1029). However, "it is ill-understood how changing market, technology and regulation conditions generally drive revisions in business models" (De Reuver et al. 2009, p.1). Helping close this gap is a valuable contribution to theory, aligning it closer to practice. Thus, the objective is "to explore the impact of augmented reality and virtual reality technologies on business model innovation in technology companies in Germany".

\section{LITERATURE REVIEW}

Emerging technological innovations and business models are profoundly linked (Baden-Fuller and Haefliger 2013), and BMI can be driven by emerging digital technologies such as AR/VR (Euchner 2016). However, most entrepreneurs don't sufficiently understand what business models are, lack the skills to design appropriate models, and fail to innovate business models, as market conditions change. Hence, further research is needed. Our discussion starts with understanding AR/VR.

\subsection{Augmented Reality and Virtual Reality: Business Model Innovation Drivers}

A conservative prediction expects the market volume of AR/VR to jump from $\$ 3$ billion in 2016, to $\$ 40$ billion by 2020 (SuperData 2017). Gartner (2016) placing AR/VR on their Top Ten strategic technology trends, conclude that "transparently immersive technologies identified within this theme are at, or over, the Peak of Inflated Expectations, ... and they are now poised to achieve real productivity". These forecasts are founded on an assessment that AR/VR have reached sufficient technological readiness (Ebert et al. 2017), "offering more opportunity than ever before to create compelling AR/VR experiences" (Billinghurst et al. 2015, p.3). Key is widespread application of AR/VR across industries. AR/VR are broadly seen as potential new training systems for maintenance and assembly tasks (Gavish et al. 2015). Similarly, AR/VR promise to be beneficial for education purposes. Many of the world's largest companies have already incorporated AR/VR into marketing strategies: "innovative marketers can now leverage AR to craft immersive brand experiences, create more interactive advertising, and enable consumers to experience products and spaces in novel ways." (Scholz and Smith 2016, p.2). For destination marketing practitioners, theme parks are a potential market for AR (Jung et al. 2015). Employing AR/VR for remote collaboration also offers novel opportunities: who can a user interact with (e.g. remote people), and how can be interacted (Greenwald et al. 2017). Further promising fields are virtual showrooms and product configurators as pioneered by Audi and IKEA.

\subsection{Business Models and Business Model Innovation}

Companies may approach the commercialisation of new technologies, through the development of business models (Brettel 2015). However, before entrepreneurs can go about innovating their business model, they need to comprehend what a business model actually is (Chesbrough 2010). Business models can serve as communication tools (Morris et al. 2005), and "as a mediating construct between technology and economic value" (Chesbrough and Rosenbloom 2002, p.532). Business models can also be a source of competitive advantage (Lüdeke-Freund 2013), as they are more difficult to imitate than product-, service-, or process-innovations (Schallmo 2013). Ultimately, it may be that "a mediocre technology pursued within a great business model may be more valuable than a great technology exploited via a mediocre business model" (Chesbrough 2010, p.354). Business models are not static, but of dynamic nature (De Reuver et al. 2009), and companies striving for sustainability, need to continuously reinvent their business models (Sharma and Gutiérrez 2010). Furthermore, BMI "can provide significant opportunities both during periods of rapid economic growth and at times of turmoil" (Giesen et al. 2010, p.17). Furthermore, new digitally-based technological innovations coupled with innovative business models disrupt industry after industry (cf. Streibich 2017).

However, BMI is challenging (Euchner 2016), perhaps even more challenging than other innovation types, such as product, process, service, or management innovations (Schallmo 2013). As a result, many 
BMI efforts fail (Christensen et al. 2016). On the one hand, these failures might be caused by the application of business model concepts which are too static (Euchner 2016). On the other hand, even innovative, fully-functional business models may fail to produce economic return for the initiator, if they don't successfully fend off (more powerful) imitators (Casadesus-Masanell and Ricart 2011). As suggested by "blue ocean strategy", "almost any business model will perform brilliantly if a company is lucky enough to be the only one in a market" (Casadesus-Masanell and Ricart 2011, p.4). Opposing, business models are likely to fail if surrounding market conditions and competitive settings are ignored.

More generally speaking, BMI refers to two different ideas: BMI in the sense of inventing or introducing entirely new business models (Christensen et al. 2016), or BMI in the context of innovating an existing business model. In the case of innovating an existing business model, the challenge arises that business models are generally designed to resist change (Christensen et al. 2016). This sends business models down a path of a potentially predictable business model life cycle or journey (Morris et al. 2015), thereby possibly failing to unlock the true potential benefits of active BMI. This is even more troubling, as continuous re-invention of an existing business is not optional these days, rather, failing to do so will debatably lead to business failure (Frary 2017). Brettel (2015) suggests that BMI might be created through the reconfiguration of business model components and business model design types. However, innovating a business model is significantly more than the mere development of a novel service or product (Frankenberger et al. 2013).

However, neither business model development nor BMI have been exhaustively investigated. The continuous rise of information and communication technologies results in the need for ever increasingly complex business models (Osterwalder and Pigneur 2004). Thus, not just technology, but business models for AR/VR must be innovative and continuously updated as well. This innovation-process however, needs to be managed, as a mal-fitting innovation-management-process may result in a lack of capturing value from innovation (Chesbrough et al. 2002). BMI is the next frontier for business model researchers, as it "represents a novel and more holistic form of organizational innovation" (Foss and Saebi 2016, p.201). Emerging technologies, such as AR/VR, trigger BMI (Casadesus-Masanell and Ricart 2011), and BMI is an essential task when attempting to capture the benefits of technology driven transformation (Lambert and Davidson 2013). Thus, BMI is defined as: the continuous process of the creation of new business models or innovating any of the business model components or their interplay namely: value proposition, customer relations, value creation mechanism, value capture and finances; or innovating its business function capacity as a communication tool, mediator between strategic objectives and technology, and/or as a source of competitive advantage.

\subsection{Research Gap and Research Contribution}

van Kleef et al. (2010) suggest there hasn't been a commercial breakthrough for AR. This perception changed somewhat as Pokemon GO resulted in surging Nintendo stock value. However, Zott et al. (2011) conclude firms need to do more than just forge technology onto products and services: if they wish to realise the commercial potential, they also need to design unique business models. Thus, digital technologies such as AR/VR are drivers for BMI (Casadesus-Masanell and Ricart 2011), and business models themselves may be shaped by technological innovations (Teece 2006). This is especially true in the high velocity environment of the internet, where business models must be frequently altered to meet new challenges. However, "it is ill-understood how changing market, technology and regulation conditions generally drive revisions in business models" (De Reuver et al. 2009, p.1). This gap motivates the authors to establish how business models of technology companies are impacted by AR/VR as it will be a valuable contribution to praxis.

\section{RESEARCH METHODOLOGY}

The research objective is "to explore the impact of augmented reality and virtual reality technologies on business model innovation in technology companies in Germany". To guide the research effort, a conceptual framework was developed, and the following four research questions were formulated:

\footnotetext{
RQ1: What types of AR/VR technologies are technology companies in Germany adopting?

RQ2: How are AR/VR technologies being applied by technology companies in Germany?

RQ3: How do AR/VR technologies impact BMI in technology companies in Germany?

RQ4: How can German technology companies maximise the benefits of AR/VR technologies for BMI?
} 


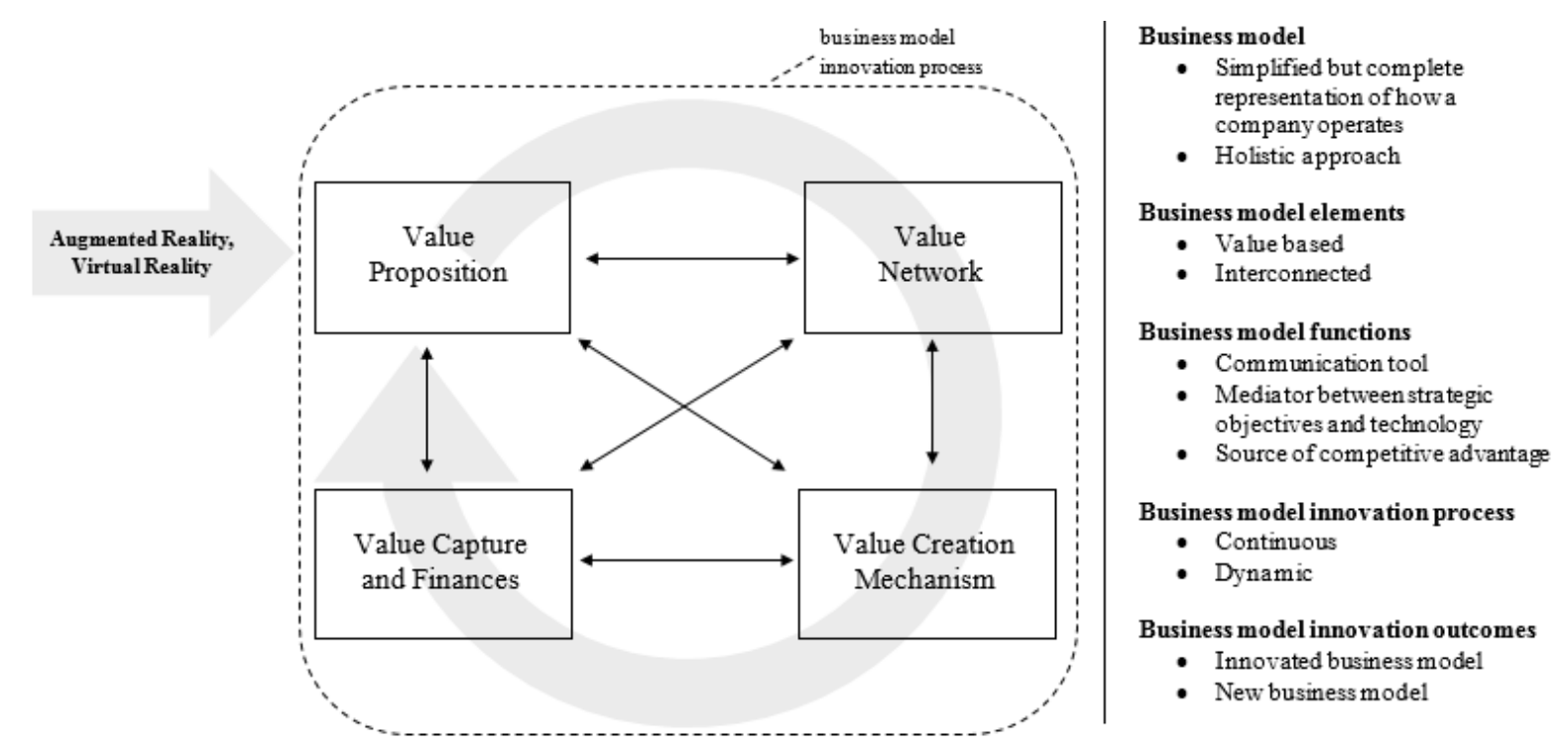

Figure 1: Conceptual Framework (adapted from Chesbrough and Rosenbloom 2002; Morris et al. 2005; Al-Debei and Avison 2010; Lüdeke-Freund 2013).

\subsection{Philosophy}

Saunders (2011) identifies three main angles to approach scientific research philosophy; namely ontology, epistemology, and axiology. Depending on the researcher's ontological position, two main knowledge-creating epistemological approaches may be taken: a positivistic or interpretivist approach. A strict positivist does not consider studying social phenomena a worthwhile effort (Bhattacherjee 2012), while strict interpretivists see no point in solely categorising phenomena in cause and effect (Holden and Lynch 2004). Axiology is concerned with the roles of the researchers' values regarding research choices (Saunders, 2011). Consequently, a researcher's philosophical approach reveals some of the researcher's values and beliefs (Saunders 2011). With reference to the two dimensions proposed by Burrell and Morgan (1979), "radical change" and "regulation", the authors hold a view of society of radical change. Furthermore, the $21^{\text {st }}$ century is a time in which the pace of change accelerates, driven by technological innovations, and an ever more interconnected world. From an ontological perspective, the social world is to a large extent constructed in our minds, by observing phenomena and then attaching interpretations and meanings to them (phenomenological). Entrepreneurial opportunities can be created, rather than discovered, and whether a technological innovation finds extensive employment or not, ultimately is a choice made by humans. This in turn, is primarily influenced by the perceived importance that social actors give to the new technology and associated phenomena. This conviction places the author in the ontological camp of subjectivism. Oftentimes, and contrary to personal beliefs, technologically-driven changes unfold slower and are much less revolutionary. Similarly in this study, slower than expected growth is occurring in the AR/VR industry (Bastian 2017), and these "order-preserving-forces" perhaps indicate, that taking a regulatory view of society is a useful approach for the study. However, some reports suggest AR/VR has momentum and a market upturn is possible (Ebert et al. 2017) though the pace of change is unclear. Therefore, it's imperative to understand what is going on in practice as a practical and insightful first step (RQs 1 and 2), before understanding how AR/VR impacts BMI (RQ3) or proposing changes (RQ4). This aligns with the interpretive paradigm rather than the radical humanist paradigm (Saunders 2011). Therefore, an interpretivist paradigm is adopted. In summary, the study adopts a phenomenological, subjectivist, interpretivist philosophy.

\subsection{Methodology}

Saunders (2011, p.4) uses "methodology" to refer to the theory of how research should be undertaken, and "methods" to refer to techniques used to obtain and analyse data. Thus, having identified an interpretivist philosophical stance, from a methodology perspective, "it tends to be nominalist, antipositivist, voluntarist and ideographic" (Burrell and Morgan 1979, p.28). The nominalist approach aims to obtain phenomenological insights, rather than attempting to build on positivistic science (Holden and Lynch 2004). Anti-positivism, employing qualitative methods, is a synonymous expression for the epistemological stance of interpretivism (Bhattacherjee 2012). Voluntarism postulates that humans can act independently and by freewill. The ideographic approach opposes the nomothetic approach and aims at highlighting the individual's interpretation of a phenomena, rather than striving to deduct law-like 
statements about social life (Burrell and Morgan 1979) by utilising quantitative methods. Consequently, the author contends, that a qualitative research methodology is well suited for the research objective.

Case study research is suitable to investigate a contemporary phenomenon in its natural context and to answer "how" or "why" questions (Yin 2017). This study aims to explore the contemporary phenomenon of AR/VR and primarily strives to answer "how" questions. Therefore, this study adopts a case study approach. Defining and bounding the case is important (Yin 2017), so the researcher understands the chosen unit of analysis as it shapes the types of data, as well as the data collection approach (Bhattacherjee 2012). Thus, the authors identify AR/VR application deployments as the unit of analysis, to understand what impact this deployment has on BMI in technology companies. Examples of cases could be the deployment of AR/VR to innovate the marketing or training process in a company, or indeed, the creation of an entirely new firm. Thus, the study adopts a phenomenologist, subjectivist, interpretivist approach using holistic "Type 3" multiple case design (Yin 2017, p.48).

Creswell (2002) categorises qualitative data collection methods as observations; interviews; documents; and, audio-visual (AV) materials. The study notes all observations as field notes. Semi-structured interviews with key players in each case is the primary source of data. Data collected through observations or interviews is commonly done by preparing data collection protocols (Creswell 2002). An interview guide and case protocol has been designed around the four research questions, and the conceptual framework also guides interview questions. The researchers primarily examine web-based documentation, consisting of case descriptions, marketing and company background information, but will consider other relevant documentation that may emerge. AV materials are treated analogous to documents. To manage data collection, the researchers developed a BMI case study database folder, a case study log, a case study mind map, and installed Redmine Project Management System.

\section{INITIAL FINDINGS}

The author developed six criteria for pre-selecting cases: significant involvement in AR/VR; case completeness; case relevance for BMI; case general applicability; access; and relevant to Germany. An online search to identify cases applied 34 key phrases arising from literature, which when combined with the terms AR/VR, resulted in 68 English and 66 German search strings. The search took several days, resulting in 230 pages of data. Negotiating case access is time-consuming, however, interest in the research is significant due to its contemporary nature, opening doors in such innovative start-ups, as the pilot (Company \#770001) and one of the largest German automotive consulting firms (\#770005).

A pre-pilot test was conducted in April 2018 with a senior AR/VR developer. The interviewee chose a VR case rolled out to a client in 2017. The project created an innovative experience for exposition visitors. The project was accompanied by printed marketing materials and coordinated activities prior to/after the exposition. The pre-pilot resulted in minor changes to interview questions and ordering. The main benefit of the pre-pilot was psychological: the novice researcher's confidence increased significantly.

The pilot case, focused on expert interviews to test and refine data collection, commenced in May 2018. In this instance, "the case" is the company itself, a Berlin-based start-up, established in 2017. Company A is seed-funded by an investment firm holding a majority share and focuses on emerging digital markets. Company A has developed innovative VR for industry collaboration but spotting the opportunities to use AR/VR to innovate its own business model, has now morphed from a productorientated start-up into an AR/VR software as a service agency. Interviews were conducted on site with the CEO and CTO. Reflecting on the research objective and research questions, the pilot case study reveals the following. RQ1: Core technologies used by German organisations identified by interviewees include Microsoft HoloLens, Oculus Rift, ODB, Photon, Unity, Vuforia, and surprisingly, standard offthe-shelf PC gaming hardware. RQ2: AR/VR are primarily used for digital assistance, to change business processes, or to support new business models. One VR collaboration product enabled instant design review, eliminating travel needs. RQ3: It became very evident that AR/VR enables significant business process transformation for clients of Company A, enabling instant feedback from stakeholders, faster decision making, drastically reduces errors (see it before you build it), results in huge cost savings, and faster development cycles. RQ4: Initial evidence suggests organisations should (i) focus initially on projects, gaining experience with AR/VR, (ii) build a framework with re-usable elements, (iii) develop in-house, outsource non-core business (iv) run very short development cycles. Furthermore, some surprises surfaced (i) slow market development, (ii) unexpected value proposition: for some clients "innovativeness in itself" provides value (iii) a clear discrepancy between business model importance and business model competence, (iv) AR/VR requires a lot of explanation for clients. 


\section{CONCLUSIONS}

The results of the pilot case and the initiation (early stages) of additional cases, lends itself to re-open the discussion on what VR/AR really is. Definitions of VR/AR are very technology-, and humanexperience focussed. From a BMI perspective, it might be wise to rethink these definitions. A refined understanding of AR/VR from BMI perspectives may also emerge as an important finding from this study. When it comes to AR/VR, it seems like numerous businesses are betting on "technologically-lessambitious" business models. Real estate agent (\#770010A) states it is now common practice in the real estate industry to present $360^{\circ}$ photographs of properties, which are for sale. These $360^{\circ}$ photographs are not presented via a virtual reality headset; rather, numerous images are combined and linked together. The result is a virtual tour which can be taken in a web browser. From a technological viewpoint, creating $360^{\circ}$ virtual tours in a web browser, is much less sophisticated than developing a fully-immersive virtual reality experience. A company thriving well on a "low-hanging-fruit approach" when deploying AR technology is INDE, who uses interactive, large-scale AR installations to "inspire, entertain, inform and educate". These business examples are less focused on leading-edge technology; and seem to be primarily centred on an innovative approach to business modelling, thereby potentially underlining the observation previously made by O'Riordan et al. (2014, p.2), that "legendary firms that shape their industry structures are in fact business-model innovators"; rather than technology leaders.

\section{REFERENCES}

Al-Debei, M.M. and Avison, D. 2010. "Developing a Unified Framework of the Business Model Concept", European Journal of Information Systems (19:3), pp 359-376.

Baden-Fuller, C. and Haefliger, S. 2013. "Business Models and Technological Innovation”, Long Range Planning (46:6), pp 419-426.

Bastian, M. 2017. Virtual Reality 2017: Das Waren Die Drei Wichtigsten Ereignisse. https://Vrodo.De/Virtual-Reality-2017-Das-Waren-Die-Drei-Wichtigsten-Ereignisse/ Retrieved 9 October 2018.

Bhattacherjee, A. 2012. Social Science Research: Principles, Methods, and Practices. Textbooks Collection. 3. http://scholarcommons.usf.edu/oa textbooks/3 Retrieved 9 October 2018.

Billinghurst, M., Clark, A., and Lee, G. 2015. "A Survey of Augmented Reality”, Foundations and Trends in Human-Computer Interaction (8:2-3), pp 73-272.

Brettel, M. 2015. RWTH Aachen Video Lecture|Geschäftsmodell-Design. www.Management.RwthAachen.De Retrieved 9 October 2018.

Burrell, G. and Morgan, G. 1979. "Two Dimensions: Four Paradigms", Sociological Paradigms and Organizational Analysis, pp 21-37.

Casadesus-Masanell, R. and Ricart, J.E. 2011. "How to Design a Winning Business Model”. Harvard Business Review, (89:1/2), pp 100-107.

Chesbrough, H. 2010. "Business Model Innovation: Opportunities and Barriers”, Long Range Planning (43:2-3), pp 354-363.

Chesbrough, H. and Rosenbloom, R.S. 2002. "The Role of the Business Model in Capturing Value from Innovation: Evidence from Xerox Corporation's Technology Spin-Off Companies”, Industrial and Corporate Change (11:3), pp 529-555.

Christensen, C.M., Bartman, T. and Van Bever, D. 2016. "The Hard Truth About Business Model Innovation”, MIT Sloan Management Review (58:1), p 31.

Creswell, J.W. 2002. Educational Research: Planning, Conducting, and Evaluating Quantitative. 4th Ed. Prentice Hall Upper Saddle River, NJ.

De Reuver, M., Bouwman, H. and MacInnes, I. 2009. "Business Model Dynamics: A Case Survey", Journal of Theoretical and Applied Electronic Commerce Research, (4:1), pp 1-11.

Ebert, D., von der Gracht, H., Lichtenau, P. and Reschke, K. 2017. "Virtual \& Augmented Reality: Neue Dimensionen der Realität. https://home.kpmg.com/content/dam/kpmg/pdf/2016/o4/virtualreality-exec-summary-de.PDF Retrieved 9 October 2018.

Euchner, J. 2016. “Business Model Innovation” Research-Technology Management (59:3), p 10. 
Foss, N.J. and Saebi, T. 2016. "Fifteen Years of Research on Business Model Innovation", http://journals.sagepub.com/doi/abs/10.1177/0149206316675927. Retrieved 9 October 2018.

Frary, M. 2017. "Businesses Need to Reinvent or Fail”, Raconteur, www.Raconteur.Net/Business/Businesses-Need-To-Reinvent-Or-Fail Retrieved 9 October 2018.

Gartner 2016. “Gartner's 2016 Hype Cycle for Emerging Technologies Identifies Three Key Trends that Organizations Must Track to Gain Competitive Advantage", https://www.gartner.com/newsroom/id/3412017 Retrieved 9 October 2018.

Gavish, N., Gutiérrez, T., Webel, S., Rodríguez, J., Peveri, M., Bockholt, U. and Tecchia, F. 2015. "Evaluating Virtual Reality and Augmented Reality Training for Industrial Maintenance and Assembly Tasks”, Interactive Learning Environments (23:6), pp 778-798.

Giesen, E., Riddleberger, E., Christner, R. and Bell, R. 2010. "When and How to Innovate your Business Model", Strategy \& Leadership (38:4), pp 17-26.

Greenwald, S., Kulik, A., Kunert, A., Beck, S., Frohlich, B., Cobb, S., Parsons, S., Newbutt, N., Gouveia, C., and Cook, C. 2017. Technology and Applications for Collaborative Learning in Virtual Reality, http://Eprints.Uwe.Ac.Uk/32215 Retrieved 9 October 2018.

Holden, M.T. and Lynch, P. 2004. "Choosing the Appropriate Methodology: Understanding Research Philosophy”, The Marketing Review (4:4), pp 397-409.

Jung, T., Chung, N. and Leue, M.C. 2015. The Determinants of Recommendations to Use Augmented Reality Technologies: The Case of a Korean Theme Park", Tourism Management (49), pp 75-86.

Van Kleef, N., Noltes, J. and Van Der Spoel, S. 2010. "Success Factors for Augmented Reality Business Models", Study Tour Pixel, pp 1-36.

Lambert, S.C. and Davidson, R.A. 2013. Applications of the Business Model in Studies of Enterprise Success, Innovation and Classification: An Analysis of Empirical Research from 1996 to 2010", European Management Journal, (31:6), pp 668-681.

Lüdeke-Freund, F. 2013. Business Models for Sustainability Innovation: Conceptual Foundations and The Case of Solar Energy.

Morris, M., Schindehutte, M. and Allen, J. 2005. “The Entrepreneur's Business Model: Toward a Unified Perspective", Journal of Business Research (58:6), pp 726-735.

O’Riordan, N., O’Reilly, P., Duane, A. and Andreev, P. 2014 “Business Model Innovation: A Temporal Perspective. The 25th ACIS, Auckland New Zealand, 8-10 December, 2014. http://researchrepository.ucd.ie/handle/10197/7268 Retrieved 9 October 2018.

Osterwalder, A. and Pigneur, Y. 2004. “An Ontology for E-Business Models”, Value Creation from EBusiness Models, pp 65-97.

Saunders, M.N. 2011. Research Methods for Business Students, 5/E. Pearson Education India.

Schallmo, D. 2013. Geschäftsmodell-Innovation. Wiesbaden: Springer Fachmedien Wiesbaden.

Sharma, S. and Gutiérrez, J.A. 2010. “An Evaluation Framework for Viable Business Models for MCommerce in the Information Technology Sector", Electronic Markets, (20:1), pp 33-52.

Scholz, J. and Smith, A.N. 2016. "Augmented Reality: Designing Immersive Experiences that Maximize Consumer Engagement”, Business Horizons (59:2), pp 149-161.

Streibich, H. 2017. Who Needs Silicon Valley? Made in Digital Germany is Europe's Big Hope. http://www.europeanbusinessreview.com/Who-Needs-Silicon-Valley-Made-In-DigitalGermany-Is-Europes-Big-Hope/ Retrieved 9 October 2018.

Superdata 2017. Superdata Research | Games Data and Market Research. https://www.Superdataresearch.com . Retrieved 9 October 2018.

Teece, D.J. 2006. “Reflections on Profiting from Innovation”, Research Policy (35:8), pp 1131-1146.

Yin, R.K. 2017. Case Study Research and Applications: Design and Methods, $6^{\text {th }}$ Edition. Los Angeles: SAGE Publications, Inc.

Zott, C., Amit, R. and Massa, L. 2011. “The Business Model: Recent Developments and Future Research”, Journal of Management (37:4), pp 1019-1042. 